\section{(A) Check for updates}

Cite this: Dalton Trans., 2018, 47 10320

\title{
Dinitrogen photoactivation: status quo and future perspectives
}

\begin{abstract}
Vera Krewald iD
While the thermal activation of the dinitrogen molecule has been demonstrated in numerous examples with a variety of transition metals and ligand frameworks, the use of light to induce a weakening or splitting of the strong $N-N$ bond is less well explored. Six complexes that bind $N_{2}$ in a linear $\mu-\eta^{1}: \eta^{1}$-end-on fashion between two transition metals are known to cleave dinitrogen after absorbing a photon and relaxing from an electronically excited state. This Perspective article reviews the molecular complexes known to be capable of dinitrogen photocleavage, and discusses mechanistic insights into the photoactivation process gained from experimental and computational studies. In an extension of previous hypotheses for pathways to dinitrogen photoactivation that would facilitate easy protonation of the $\mu-\mathrm{N}$ atoms, a scheme is presented that may help to identify other complexes that could be capable of dinitrogen photoactivation.
\end{abstract}

Received 1st February 2018
Accepted 19th April 2018

DOI: $10.1039 / \mathrm{c} 8 \mathrm{dt} 00418 \mathrm{~h}$

rsc.li/dalton

\section{Introduction}

The first sentence of a review by Chatt and Leigh from 1972 reads: "Nitrogen fixation is topical and the subject of many detailed reviews". ${ }^{1}$ Despite almost 50 years having passed since, this description of the field remains accurate to date, which should of course not be interpreted as a lack of progress. In fact, many milestones towards a better understanding of dinitrogen fixation in nature, in industry and in the development of novel catalysts in many laboratories have been achieved in the past decades: besides Nobel prizes to Fritz Haber in 1918 "for the synthesis of ammonia from its elements" 2 and to Gerhard Ertl in 2007 "for his studies of chemical processes on solid surfaces", in particular the Haber-Bosch process, ${ }^{3}$ the atomic-level description of the active site of nitrogenase $e^{4-6}$ and the first molecular complexes that cleave dinitrogen thermally ${ }^{7}$ or photochemically ${ }^{8}$ were achieved. Dinitrogen activation remains a challenging field of research, fuelled by the wish to ever better understand nitrogen fixation in nature, and the need to develop catalysts that can directly incorporate air-derived nitrogen atoms into useful chemicals. The key reasons why dinitrogen remains difficult to break and utilise are the same as recognised decades ago: a dissociation enthalpy of $944 \mathrm{~kJ} \mathrm{~mol}^{-1}$ due to its triple bond, an ionisation potential of $15.6 \mathrm{eV}(c f .14 .0 \mathrm{eV}$ for $\mathrm{CO}$ ), a large HOMO-LUMO gap, and the lack of a dipole moment. ${ }^{1}$

The industrial route to ammonia, the Haber-Bosch process, is energy efficient and well established with an annual pro-

Department of Chemistry, University of Bath, Claverton Down, Bath, BA2 7AY, UK. E-mail:v.krewald@bath.ac.uk duction in 2015 that consumed $c a .1 \%$ of the world energy production. ${ }^{9,10}$ The overwhelming majority of the ammonia produced with the Haber-Bosch process is used to generate artificial fertiliser. While the question of whether the process could be replaced by an alternative that relies on molecular catalysts remains open, the Haber-Bosch process in its current form is not without problems. It consumes fossil hydrogen from natural gas, in quantities that amount to $c a .2 \%$ of the world annual production, ${ }^{9}$ so that it is overall unsustainable; however, this could probably be remedied once a water oxidation catalyst that is capable of producing renewable hydrogen in an industrial scale is found and established. ${ }^{11,12}$

The ongoing search for $\mathrm{N}_{2}$-to- $\mathrm{NH}_{3}$-converting molecular complexes has ramifications beyond any potential industrial use. First of all, there is scientific curiosity as to the atomiclevel details of this process, and much to be learned from the chemical clarity and elegance of molecular catalysts capable of small molecule activation. Equally, the study of molecular complexes helps to unravel the mechanism of dinitrogen activation in nature. ${ }^{13-18}$ Besides biochemical, spectroscopic and computational efforts to shed light on this key reaction, ${ }^{14,19}$ synthetic complexes that mimic the molecular structure and electronics of the active site(s) have been of great utility. ${ }^{20}$ Despite significant advances in the understanding of the molecular composition and electronic structure of the nitrogenfixing cofactor(s) in enzymes, the precise mechanism remains clouded. ${ }^{14,21-23}$

Most bulk and fine chemicals are currently sourced from fossil resources, including important $\mathrm{N}$-heterocyclic compounds. Clearly, the economic pressure is currently not sufficiently high to prevent mankind from burning these pre- 
cious resources. It is, however, equally clear that alternative approaches and methods will be required at some point in the future to maintain the ubiquity of synthetic materials that we have come to depend on. These approaches may include recycling of existing $\mathrm{N}$-containing materials, the valorisation of natural sources such as proteins, and the incorporation of airderived nitrogen atoms into valuable chemicals. The latter idea motivates the search for catalysts that can activate or split dinitrogen and subsequently form $\mathrm{N}-\mathrm{E}$ bonds ( $\mathrm{E}=$ main group element, e.g. $\mathrm{C}, \mathrm{H}, \mathrm{Si}) .^{24,25}$

Two different targets of dinitrogen fixation can be distinguished: one that aims to produce ammonia, i.e. reduces nitrogen, and one that aims to produce $\mathrm{N}$-incorporated products, in which the nitrogen atom may be formally oxidised or reduced. The requirements for catalysts that are capable of carrying out these reactions are of course not mutually exclusive, but they may differ, potentially affecting the metal identity, the metal oxidation states, their oxidative or reductive power, the hapticity of the ligands, and the need for internal acids or bases among many other chemical parameters.

The targeted chemical space for products resulting from dinitrogen fixation is vast, however, the principal approach to activate or cleave the $\mathrm{N}-\mathrm{N}$ triple bond relies on a catalyst that binds $\mathrm{N}_{2}$ and then weakens the $\mathrm{N}-\mathrm{N}$ interaction so that the nitrogen atoms are primed to form new bonds. The energy required to enable this reaction sequence is usually derived thermally. A less explored route to activate or cleave dinitrogen is a photochemical process, ${ }^{26}$ and consequently, our current knowledge of this route is insufficient to systematically and strategically optimise dinitrogen photocleavage catalysts.

This perspective aims to review the field of molecular dinitrogen photoactivation, to identify shared principles among the complexes relevant to this reaction, and to indicate possible paths to a better understanding of the photophysical and photochemical processes. We begin with a brief summary of the nature of metal-nitrogen interactions and highlight a few examples of thermal dinitrogen fixing complexes and catalysts, before exploring in greater detail the photochemical dinitrogen activation systems.

\section{Nitrogen binding in metal complexes}

The nature of the interaction between dinitrogen and metals has been covered in many excellent reviews, ${ }^{27,28}$ and only a few key points are summarised here. Dinitrogen is generally not a good ligand: it does not have a dipole moment and is a weaker $\sigma$-donor and $\pi$-acceptor than isoelectronic CO. ${ }^{28,29}$ The strength and character of the nitrogen-metal interaction alters the nitrogen-nitrogen interaction, i.e. $\mathrm{N}_{2}$ is activated by depletion of electron density from its bonding orbitals $(\sigma$ donor) and donation into its antibonding orbitals ( $\pi$-acceptor), Fig. 1a. The resulting overall $\mathrm{N}-\mathrm{N}$ bond strength - equivalent to the degree of activation - can be determined from the $\mathrm{N}-\mathrm{N}$ distance in crystal structures, or measured by the N-N stretch- (a)
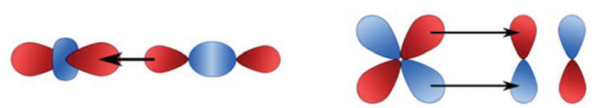

(b) $\begin{array}{ll}M-N \cdots N & \eta^{1} \\ M-N \cdots N-M & \mu-\eta^{1}: \eta^{1}\end{array}$
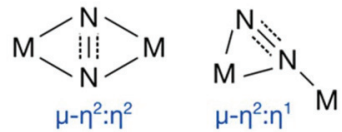

Fig. 1 (a) Electronic interactions in end-on $\mathrm{M}-\mathrm{N}-\mathrm{N}$ complexes: $\sigma-$ donor (left) and $\pi$-acceptor pathways (right). (b) Binding modes in mono- and di-nuclear metal complexes of dinitrogen; the $\mu-\eta^{1}: \eta^{1}$-endon configuration can be linear, cis or trans.

ing frequency, which can then be translated into an estimate for the $\mathrm{N}-\mathrm{N}$ distance according to Badger's rule. ${ }^{28,30}$

Dinitrogen can bind $\eta^{1}$-end-on, $\mu-\eta^{1}: \eta^{1}$-end-on, $\mu-\eta^{2}: \eta^{2}$ side-on, and $\mu-\eta^{1}: \eta^{2}$-side-on; the $\eta^{1}$-side-on motif remains unisolated (see Fig. 1b). ${ }^{27}$ Side-on vs. end-on coordination can be subtly influenced by the extent of nonbonded steric interactions. ${ }^{31}$ Electronically, dinitrogen is formally bound as $\mathrm{N}_{2}$, $\mathrm{N}_{2}{ }^{-}, \mathrm{N}_{2}{ }^{2-}, \mathrm{N}_{2}{ }^{3-}$ and $\mathrm{N}_{2}{ }^{4-}$ with varying spin states, although in comparison with the more electron-accepting $\mathrm{O}_{2}$ molecule, the more reduced forms are formed with more strongly reducing metals. $^{28}$

\section{Thermal routes to dinitrogen activation}

$\mathrm{N}_{2}$ is cleaved with elemental $\mathrm{Li}$ to yield $\mathrm{Li}_{3} \mathrm{~N}$, and complexes containing $\mathrm{Cr}, \mathrm{Mo}, \mathrm{W}, \mathrm{Fe}$ and $\mathrm{Ti}$ in reaction mixtures with $\mathrm{LiAlH}_{4}, \mathrm{RMgX}, \mathrm{RLi}$, or $\mathrm{R}_{3} \mathrm{Al}$ have also been known to produce $\mathrm{NH}_{3}$ from $\mathrm{N}_{2}$ since at least the 1960 s. $^{32}$ To reductively cleave dinitrogen, six electrons are required, i.e. at least a $\mathrm{d}^{3}-\mathrm{d}^{3}$ configuration or equivalent in a transition metal dimer. The first report of a well-defined transition metal complex capable of spontaneous thermal dinitrogen splitting was by Laplaza and Cummins in 1995: ${ }^{7}$ a three-coordinate $\mathrm{Mo}(\mathrm{III})\left(\mathrm{d}^{3}\right)$ complex with three NRAr $\left(\mathrm{R}=\mathrm{Me}_{3} \mathrm{C}, \mathrm{Ar}=3,5-\mathrm{C}_{6} \mathrm{H}_{3} \mathrm{Me}_{2}\right)$ ligands was shown to bind dinitrogen end-on, attach a second Mo(III) unit resulting in $\left[(\mathrm{NRAr})_{3} \mathrm{Mo}\left(\mu-\mathrm{N}_{2}\right) \mathrm{Mo}(\mathrm{NRAr})_{3}\right]$ with a linear $\mathrm{Mo}-\mathrm{N}-$ $\mathrm{N}-\mathrm{Mo}$ unit, Fig. 2a, and subsequently cleave the $\mathrm{N}-\mathrm{N}$ bond at $30{ }^{\circ} \mathrm{C}$. The transition state is thought to be of 'zig-zag'-shape, see Fig. 2b. Chemically unassisted thermal dinitrogen cleavage reactions, i.e. without an added source of reducing equivalents, yielding a transition metal nitrido product remain rare, with only a few reported in the literature to date.

One of the most famous molecular catalytic systems capable of activating dinitrogen was developed by Yandulov and Schrock, ${ }^{33,34}$ an extension of Schrock's earlier work on molybdenum complexes with triamidoamine ligands. ${ }^{35}$ The design principle that presumably leads to a closed catalytic cycle without significant decomposition or dimerisation of chemical intermediates is the formation of a pocket by the three $2,4,6-{ }^{\mathrm{i}} \mathrm{Pr}_{3} \mathrm{C}_{6} \mathrm{H}_{2}$ rings attached to the amido-nitrogens of the ligand, in which the molybdenum nitrido unit is protected. 


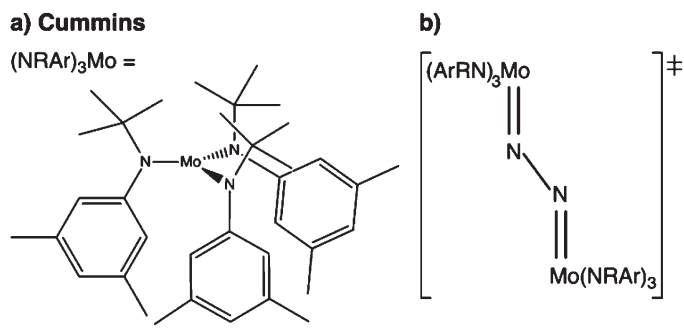

$\mathrm{Mo}(\operatorname{ArRN})_{3}=--\mathrm{N}=\mathrm{N}=--\mathrm{Mo}(\mathrm{NRAr})_{3}$

c) Sellmann

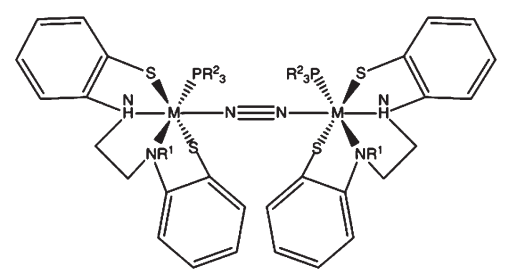

d) Peters
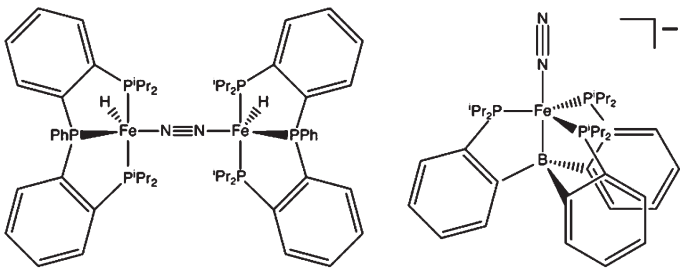

Fig. 2 Thermal dinitrogen activation complexes: (a) Cummins, (b) zigzag transition state relevant to the Cummins complex, (c) Sellmann, (d) Peters: left $\left[\mathrm{P}_{2}{ }^{\mathrm{P}^{\prime} \mathrm{Ph}} \mathrm{FeH}\right]_{2}\left(\mu-\mathrm{N}_{2}\right)$, right $\left[\mathrm{P}_{3}{ }^{\mathrm{B}} \mathrm{Fe}\left(\mathrm{N}_{2}\right)\right]^{-}$.

A different ligand design idea was pursued by Sellmann, with the aim of coupling proton and electron transfer steps: ${ }^{36-38}$ the ligand contains thiolate groups, which can be protonated and deprotonated relatively easily, Fig. 2c. Mononuclear iron complexes of the Sellmann ligand bind $\mathrm{NH}_{3}$ and $\mathrm{N}_{2} \mathrm{H}_{4}$, and $\mathrm{N}_{2} \mathrm{H}_{2}$ is found to bridge two iron centres stabilised by such a ligand. ${ }^{39}$ A ruthenium ion binds $\mathrm{N}_{2}$ end-on, ${ }^{40}$ and ruthenium dimers with bridging $\mathrm{N}_{2}$ and $\mathrm{N}_{2} \mathrm{H}_{2}$ were isolated and characterised as well. ${ }^{41}$

In recent years, Nishibayashi and coworkers have developed a series of complexes for dinitrogen activation that are based around PNP, PPP and PCP pincer-type ligands, which stabilise a range of transition metals (e.g. $\mathrm{Mo}, \mathrm{Cr}, \mathrm{Fe}, \mathrm{Co})$ and produce ammonia from $\mathrm{N}_{2} \cdot{ }^{42-45}$

Many more complexes capable of activating and transforming dinitrogen have been synthesised and characterised, and a number of thorough reviews summarising the current state of the art are available. ${ }^{24,46-54}$

\section{Photochemical routes to dinitrogen activation}

The concept of dinitrogen photoactivation holds the promise to use sunlight as the energy source for one of the most difficult small molecule activation reactions, while at the same time storing the energy in a useful form by generating valuable intermediates or chemicals. To the best of the author's knowledge, dinitrogen photoactivation and -cleavage was first discussed by Fischler and von Gustorf in $1975 .^{55}$ They introduced the idea that particular electronic excitations would lead to distinct geometric and electronic changes of a dinitrogen molecule bound to a transition metal, which would in turn alter the chemical reactivity of this $\mathrm{N}_{2}$ entity. ${ }^{55}$ Specifically, they hypothesised for an end-on $\mathrm{Fe}-\mathrm{N}_{2}$ complex that (i) d-d-transitions would depopulate an $\mathrm{Fe}-\mathrm{N} \pi$-orbital and fill an $\mathrm{Fe}-\mathrm{N} \sigma^{*}$ orbital, thus weakening the $\mathrm{Fe}-\mathrm{N}$ bond twofold and inducing its homolytic cleavage (Fig. 3, orange arrow); and (ii) LMCT transitions would populate an $\mathrm{N}-\mathrm{N} \pi^{*}$-orbital, thus increasing the basicity of the nitrogen atoms and facilitating their protonation (Fig. 3, blue arrow).

The first experimental evidence for molecular dinitrogen photoactivation was published in $2001,{ }^{8}$ followed by further examples in $2008,{ }^{56} 2010,{ }^{57} 2014^{58}$ and $2015,{ }^{31}$ alongside computational studies into plausible mechanisms in $2004^{59}$ and $2018{ }^{60}$ In all of these examples, the molecular catalyst acts directly as the photosensitizer. Dinitrogen photoactivation has furthermore been shown to occur on surfaces, which was also studied computationally. ${ }^{61-66}$ A photochemical route to the activation or cleavage of dinitrogen is thus a well-founded concept that warrants further experimental and theoretical exploration.

In the following, we will discuss three categories of complexes relevant to dinitrogen photoactivation; those that (i) show increased turnover upon irradiation, (ii) yield metalnitrido products, and (iii) directly incorporate $\mathrm{N}_{2}$-derived nitrogen atoms into molecules. It should be noted that there are also $\mu-\mathrm{N}_{2}$ dimers that form from metal nitrido complexes, both thermally and under irradiation, which is an obviously undesired side reaction to any light-induced dinitrogen splitting reaction. ${ }^{58,67-73}$

\section{Complexes that show increased turnover upon irradiation}

The Peters group has shown that for two of their iron complexes the yield of ammonia increases upon irradiation of the

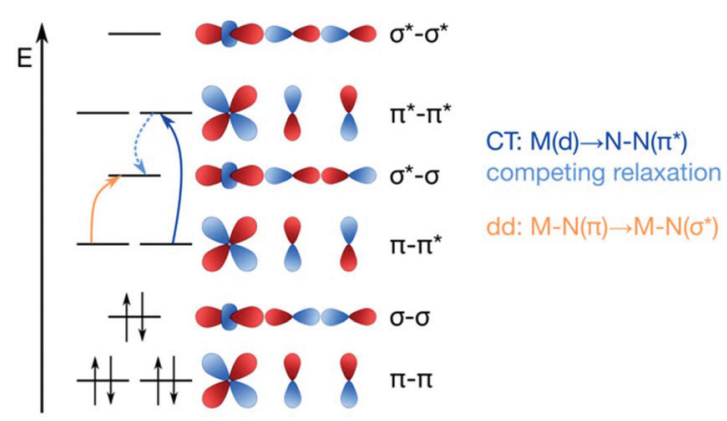

Fig. 3 Two theoretical pathways relevant to dinitrogen photocleavage according to Fischler and von Gustorf for an Fe- $\eta^{1}-\mathrm{N}_{2}$ complex (metal d-electrons not specified). Orange: $M-N(\pi)$ to $M-N\left(\sigma^{*}\right)$ excitation; dark blue: $M(d)$ to $N-N\left(\pi^{*}\right)$ excitation, shown here as $M(d)$ is the $M-N\left(\pi-\pi^{*}\right)$ orbital; light blue: competing relaxation into $\mathrm{M}-\mathrm{N}\left(\sigma^{*}\right) .^{55}$ 
reaction mixture with a $\mathrm{Hg}$ lamp. ${ }^{74}$ These complexes are a $\mu-\eta^{1}: \eta^{1}$-bridged dimer, $\left[\mathrm{P}_{2}{ }^{\mathrm{P}^{\prime} \mathrm{Ph}} \mathrm{FeH}\right]_{2}\left(\mu-\mathrm{N}_{2}\right)$, and an $\eta^{1}$-bound monomer, $\left[\mathrm{P}_{3}{ }^{\mathrm{B}} \mathrm{Fe}\left(\mathrm{N}_{2}\right)\right]^{-}$, Fig. 2d. The turnover numbers of $\mathrm{N}_{2}$ to $\mathrm{NH}_{3}$ with $\mathrm{HBAr}^{\mathrm{F}}{ }_{4}$ were significantly increased under $\mathrm{Hg}$ lamp irradiation but otherwise identical conditions. Mechanistic investigations support the idea that light-induced elimination of $\mathrm{H}_{2}$ might lead to $\mathrm{P}_{2}{ }^{\mathrm{P}^{\prime} \mathrm{Ph}} \mathrm{Fe}^{0}\left(\mathrm{~N}_{2}\right)$ as a plausible photoproduct, which acts as the catalyst. ${ }^{74}$ A direct role of electronically excited states in the activation of the $\mathrm{N}-\mathrm{N}$ bond was thus not shown conclusively.

\section{Complexes that yield metal nitrido products}

The first complex for which the light-induced cleavage of a bridging dinitrogen was shown experimentally is $\left[\mathrm{Mes}_{3} \mathrm{Mo}^{\mathrm{V}}(\mu-\right.$ $\mathrm{N}_{2}$ ) $\mathrm{Mo}^{\mathrm{V}} \mathrm{Mes}_{3}$ ] (Mes: 2,4,6- $\mathrm{Me}_{3} \mathrm{C}_{6} \mathrm{H}_{2}$ ), Fig. 4a, in which the Mo$\mathrm{N}$ and $\mathrm{N}-\mathrm{N}$ interactions were characterised as double and single bonds, respectively. ${ }^{8}$ Notably, the complex is thermally stable, but cleaves the $\mathrm{N}-\mathrm{N}$ bond upon irradiation with UVlight $(\lambda=365 \mathrm{~nm})$. The final product in this reaction is the mono- $\mu-\mathrm{N}$ complex $\left[\mathrm{Mes}_{3} \mathrm{Mo}(\mu-\mathrm{N}) \mathrm{MoMes}_{3}\right]$. The authors suggest that this product forms upon reaction of the initial photocleavage product, the Lewis-basic $\left[\mathrm{Mes}_{3} \mathrm{Mo}^{\mathrm{VI}}(\mathrm{N})\right]$, with

\section{a) Solari/Floriani}

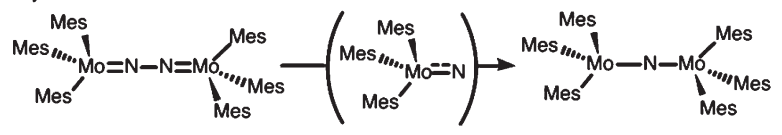

b) Curley/Cummins

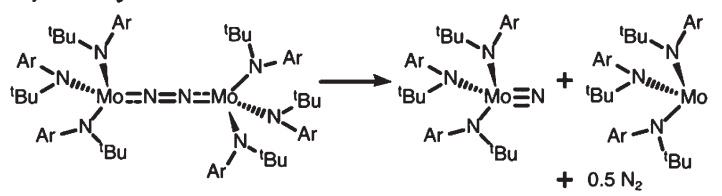

c) Kunkely/Nogler

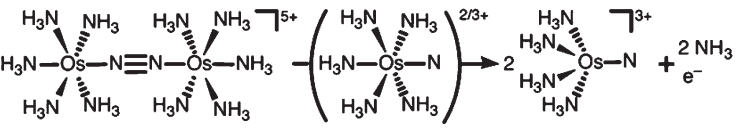

d) Miyazaki/Nishibayashi

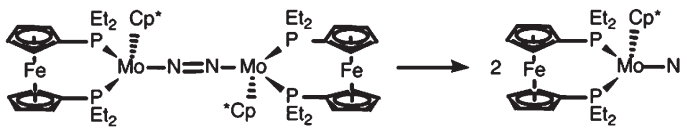

e) Keane/Sita

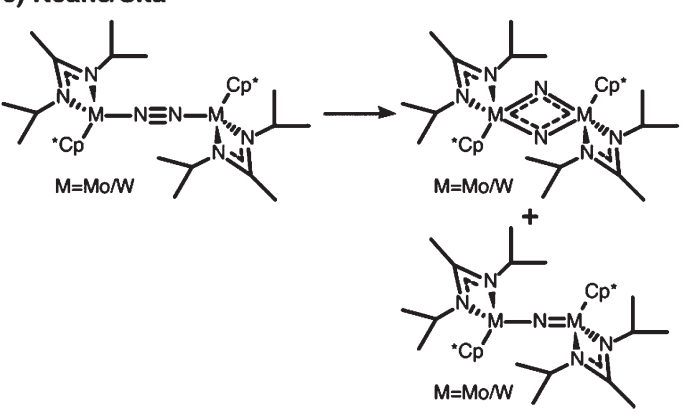

Fig. 4 Complexes shown to be active in dinitrogen photoactivation: (a) Solari et al.; ${ }^{8}$ (b) Curley et al.; ${ }^{56}$ (c) Kunkely et al.; ${ }^{57}$ (d) Miyazaki et al.; ${ }^{58}$ (e) Keane et al. ${ }^{31}$ unreacted $\left(\mu-\mathrm{N}_{2}\right)$ dimer. The product of two such coupling reactions would be $\left[\operatorname{Mes}_{3} \operatorname{Mo}(\mu-\mathrm{N}) \operatorname{MoMes}_{3}\left(\mu-\mathrm{N}_{2}\right) \operatorname{MoMes}_{3}(\mu-\mathrm{N})\right.$ $\mathrm{MoMes}_{3}$ ], which upon expulsion of the central dinitrogen unit would form two mono- $\mu-\mathrm{N}$ molybdenum dimers, Fig. $5 \mathrm{a} .{ }^{8}$ The authors furthermore note that although there are structural similarities between $\left[\mathrm{Mes}_{3} \mathrm{Mo}^{\mathrm{V}}\left(\mu-\mathrm{N}_{2}\right) \mathrm{Mo}^{\mathrm{V}} \mathrm{Mes}_{3}\right]$ and the $\left[(\mathrm{NRAr})_{3} \mathrm{Mo}\left(\mu-\mathrm{N}_{2}\right) \mathrm{Mo}(\mathrm{NRAr})_{3}\right]$ complex by Cummins and coworkers ${ }^{7}$ introduced above, the ligands in the latter have $\sigma$ and $\pi$-donor properties. This would explain the thermal stability of their complex in contrast to the thermally induced dinitrogen splitting activity of the Cummins complex.

Interestingly, the Laplaza/Cummins complex capable of thermal dinitrogen splitting was later shown to also be capable of photochemical dinitrogen splitting. ${ }^{56,75}$ With a view to the first computational study of dinitrogen photoactivation

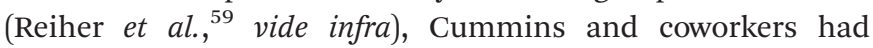
reasoned that the geometry of the excited state predicted by Reiher et al. resembled the well-known 'zig-zag' intermediate identified in computational studies of the thermal dinitrogen

a)

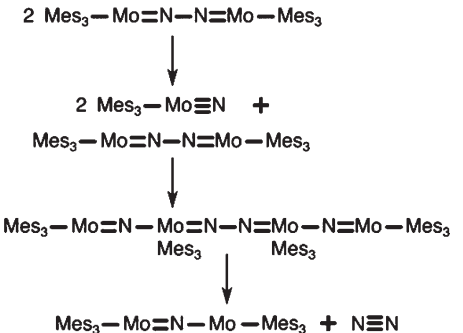

b)

c)

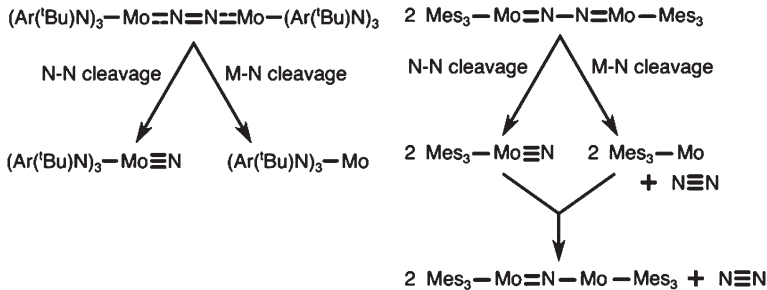

d)

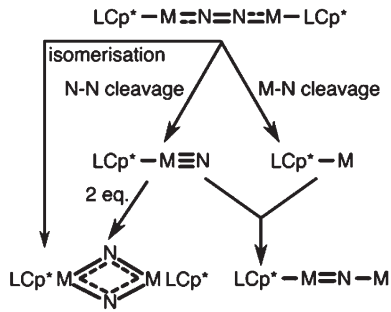

Fig. 5 Bifurcated reaction pathways in dinitrogen photocleavage and possible alternative routes to observed products. (a) Proposed reaction sequence to the observed mono- $\mu-\mathrm{N}$ product of Solari et al. ${ }^{8}$ (b) Bifurcated photochemical routes according to Curley et al. for the Laplaza-Cummins system. ${ }^{56,75}$ (c) Proposed alternative mechanism to the mono- $\mu-\mathrm{N}$ product of Solari et al. according to Curley et $a^{56}{ }^{56}$ (d) Possible pathways to products observed in Keane et al., ${ }^{31}$ photoinduced isomerisation of the $\mu-\mathrm{N}_{2}$ complex to the bis- $\mu-\mathrm{N}$ complex, dimerisation of two metal nitrido complexes after $\mathrm{N}-\mathrm{N}$ photocleavage to the bis- $\mu-\mathrm{N}$ complex, and formation of the mono- $\mu-\mathrm{N}$ product analogous to (c). 
activation pathway, Fig. $2 \mathrm{~b}$. Indeed, irradiation of the intense visible absorption band $(544 \mathrm{~nm})$ of $\left[(\mathrm{NRAr})_{3} \mathrm{Mo}\left(\mu-\mathrm{N}_{2}\right) \mathrm{Mo}\right.$ $\left.(\mathrm{NRAr})_{3}\right]$ with a $\mathrm{Hg}-\mathrm{Xe}$ arc lamp (546 nm) at low temperatures to suppress the thermal cleavage process resulted in a bleach at $542 \mathrm{~nm}$ and an increased absorbance at $c a .430 \mathrm{~nm} .{ }^{56}$ The authors observed the anticipated $\left[(\mathrm{NRAr})_{3} \mathrm{MoN}\right]$ product from homolytic $\mathrm{N}_{2}$ splitting, as well as a $\left[(\mathrm{NRAr})_{3} \mathrm{Mo}\right]$ monomer with a vacant coordination site.

Importantly, this finding implies a bifurcated reaction pathway: 'unproductive' metal-nitrogen bond cleavage on one hand, and the desired nitrogen-nitrogen bond cleavage on the other, Fig. 5b. Based on their observations, Cummins and coworkers re-interpreted the findings by Solari et al., ${ }^{8}$ suggesting that the final mono- $\mu-\mathrm{N}$ complex $\left[\mathrm{Mes}_{3} \mathrm{Mo}(\mu-\mathrm{N}) \mathrm{MoMes}_{3}\right]$ might be formed upon coupling of a $\left[\mathrm{Mes}_{3} \mathrm{Mo}\right.$ ] fragment (resulting from Mo-N scission) and a $\left[\mathrm{Mes}_{3} \mathrm{Mo}(\mathrm{N})\right]$ fragment (resulting from $\mathrm{N}-\mathrm{N}$ scission), Fig. $5 \mathrm{c}^{56}$ Unlike for the Mes-substituted complex, the (NRAr)-substitution is too bulky to allow the formation of a mono- $\mu-\mathrm{N}$ complex as was shown explicitly by Johnson et al. ${ }^{76}$

In 2010, Kunkely and Vogler investigated the propensity of the mixed-valent, valence-delocalised system $\left[\mathrm{Os}_{2}^{(\mathrm{II}, \mathrm{III})}\left(\mu-\mathrm{N}_{2}\right)\right.$ $\left.\left(\mathrm{NH}_{3}\right)_{10}\right]^{5+}$ for light-induced $\mathrm{N}-\mathrm{N}$ bond splitting, Fig. $4 \mathrm{e}^{57}$ They reasoned that its stability in aqueous solution, the intense colours of the starting compound and reaction product, and the rather unactivated $\mathrm{N}-\mathrm{N}$ bond made for an ideal test case. Irradiation of a solution of $\left[\mathrm{Os}_{2}^{(\mathrm{II}, \mathrm{III})}\left(\mu-\mathrm{N}_{2}\right)\left(\mathrm{NH}_{3}\right)_{10}\right]^{5+}$ at wavelengths shorter than $450 \mathrm{~nm}$ resulted in bleaching of its green colour and the formation of an osmium-nitrido product, $\left[\mathrm{Os}^{\mathrm{VI}}(\mathrm{N})\left(\mathrm{NH}_{3}\right)_{4}\right]^{3+} \cdot{ }^{57}$ It was also shown that intermittently, $\left[\mathrm{Os}^{\mathrm{VI}}(\mathrm{N})\left(\mathrm{NH}_{3}\right)_{5}\right]^{3+}$ is formed and thus the authors inferred that a second immediate product must be $\left[\mathrm{Os}^{\mathrm{V}}(\mathrm{N})\left(\mathrm{NH}_{3}\right)_{5}\right]^{2+}$ which would subsequently disproportionate. ${ }^{57}$ One ammonia ligand in each of the initial photoproducts is lost due to the strong trans-influence of the nitrido group.

Kunkely and Vogler furthermore carried out a similar experiment with $\left[\mathrm{Os}_{2}^{(\mathrm{III}, \mathrm{III})}\left(\mu-\mathrm{N}_{2}\right)\left(\mathrm{NH}_{3}\right)_{10}\right]^{6+}$, which might yield directly the two desired Os(vi) nitrido complexes. However, this one-electron oxidised complex 'vigorously' expels dinitrogen upon irradiation of its aqueous solution, as it also occurs thermally at temperatures above $5{ }^{\circ} \mathrm{C} .{ }^{57}$ These two structurally similar, but mechanistically disparate complexes thus showcase that a delicate electronic structure balance is required to achieve light-induced dinitrogen splitting. The osmium complexes are an example of the two reaction paths discussed above - metal-nitrogen bond scission and nitrogen-nitrogen bond scission - occurring in two closely related complexes.

Nishibayashi and coworkers isolated a series of complexes of the general formula $\left[(\operatorname{depf})\left(\mathrm{Cp}^{*}\right) \mathrm{Mo}\left(\mu-\mathrm{N}_{2}\right) \mathrm{Mo}\left(\mathrm{Cp}^{*}\right)(\mathrm{depf})\right]^{n+}$ (depf $=1,1^{\prime}$-bis(diethylphosphino)ferrocene), Fig. $4 \mathrm{~d}$, in which the bridging dinitrogen unit is formally $\left[\mathrm{N}_{2}\right]^{4-}(n=+2),\left[\mathrm{N}_{2}\right]^{3-}$ $(n=+1),\left[\mathrm{N}_{2}\right]^{2-}(n=0) .{ }^{58}$ Concomitant with an $\mathrm{N}-\mathrm{N}$ bond length decrease as the charge increases, the calculated $\mathrm{N}-\mathrm{N}$ Mayer bond order rises from 1.40 to 1.60 and $1.80 .^{58}$ The most reduced complex in this series cleaves the $\mathrm{N}-\mathrm{N}$ bond upon irradiation with visible light $(\lambda>400 \mathrm{~nm})$ in benzene solution, yielding two Mo(Iv) nitrido complexes, [(depf)(Cp*)Mo(N)]. Excitation with wavelengths above $580 \mathrm{~nm}$ did not induce a reaction. Interestingly, the monomeric photoproduct [(depf) $\left.\left(\mathrm{Cp}^{*}\right) \mathrm{Mo}(\mathrm{N})\right]$, which does not carry significant $\mathrm{N}$-based spin density according to DFT calculations, re-forms the dimeric structure upon chemical oxidation. ${ }^{58}$ The monomer can be protonated with 1,4-cyclohexadiene/FcBAr ${ }_{4}{ }_{4}$ and $[\mathrm{LutH}]\left[\mathrm{FcBAr}_{4}^{\mathrm{F}}{ }_{4}\right]$ (LutH $=2$,6-lutidinium). Similarly to the case of the two osmium dimers discussed above, only this specific complex in the redox series is active in dinitrogen photocleavage: irradiation of $\left[(\operatorname{depf})\left(\mathrm{Cp}^{*}\right) \mathrm{Mo}\left(\mu-\mathrm{N}_{2}\right) \mathrm{Mo}\left(\mathrm{Cp}^{*}\right)(\mathrm{depf})\right]^{+/ 2+}$ was ineffective.

\section{Complexes that incorporate $\mathbf{N}$-atoms into molecules}

A very interesting pair of complexes was published by Sita and coworkers in 2015: ${ }^{31} \mu-\eta^{1}: \eta^{1}$-dinitrogen-bridged Mo and $\mathrm{W}$ dimers that produce isocyanate derivatives from $\mathrm{CO}_{2}$ and $\mathrm{R}_{3} \mathrm{ECl}(\mathrm{E}=\mathrm{C}, \mathrm{Si}, \mathrm{Ge})$ upon irradiation with light, Fig. 4e. ${ }^{31}$ The dimers are of the general formula $\left[\mathrm{L}\left(\mathrm{Cp}^{*}\right) \mathrm{M}\left(\mu-\mathrm{N}_{2}\right) \mathrm{M}\left(\mathrm{Cp}^{*}\right) \mathrm{L}\right]$ with $\mathrm{M}$ either $\mathrm{Mo}$ or $\mathrm{W}\left(\mathrm{L}=\mathrm{N}\left({ }^{\mathrm{i}} \mathrm{Pr}\right) \mathrm{C}(\mathrm{Me}) \mathrm{N}\left({ }^{\mathrm{i}} \mathrm{Pr}\right)\right)$, and are thermally stable in hydrocarbon solution up to $100{ }^{\circ} \mathrm{C} .{ }^{31}$ These complexes are analogues of the previously published Ta, Hf, $\mathrm{Zr}$ and Ti dimers with the same ligand framework, ${ }^{77,78}$ some of which can also be reacted further to form N-Si bonds. ${ }^{79}$ A molybdenum dimer with a less bulky ligand $\left(\mathrm{L}^{\prime}=\mathrm{N}(\mathrm{Et}) \mathrm{C}(\mathrm{Ph}) \mathrm{N}(\mathrm{Et})\right)$ produces $\mathrm{HN}\left(\mathrm{SiMe}_{3}\right)_{2}$ in a three-step catalytic cycle from $\mathrm{N}_{2}$, $\mathrm{Me}_{3} \mathrm{SiCl}$ and a proton source with a formal overall $\mathrm{Mo}$ (II)/ Mo(Iv) redox process. ${ }^{80}$

Upon irradiation of the Mo complex with a Rayonet carousel of a medium-pressure $\mathrm{Hg}$ lamp, several photoproducts appear to form based on the UV/vis spectral changes over time. In fact, two products could be crystallised in the case of Mo: a $\left[\mathrm{L}\left(\mathrm{Cp}^{*}\right) \mathrm{Mo}^{\mathrm{V}}(\mu-\mathrm{N})_{2} \mathrm{Mo}^{\mathrm{V}}\left(\mathrm{Cp}^{*}\right) \mathrm{L}\right]$ dimer with a diamondshaped core, and a mono- $\mu-\mathrm{N}$ complex of the formula $\left[\mathrm{L}\left(\mathrm{Cp}^{*}\right)\right.$ $\left.\mathrm{Mo}^{\mathrm{III}}(\mu-\mathrm{N}) \mathrm{Mo}^{\mathrm{IV}}\left(\mathrm{Cp}^{*}\right) \mathrm{L}\right]$. Based on the latter, immediate analogies to the interpretation of the Floriani and Cummins complexes can be drawn: here, too, two competing photoactivation pathways may be at play, Mo-N and $\mathrm{N}-\mathrm{N}$ cleavage, Fig. $5 \mathrm{~d}$. As an alternative route to the diamond-shaped dimer, one can imagine that two metal nitrido products dimerise to form the bis- $\mu-\mathrm{N}$ complex, Fig. $5 \mathrm{~d}$. However, it is equally possible that the dimer with a diamond-shaped core is a true photoproduct from an isomerisation process. This means that photochemical pathways beyond the established 'zig-zag' structure must be considered and probed to fully unravel the processes in dinitrogen photocleavage. For the $\mathrm{W}$ complex, irradiation produces well-defined isosbestic points in the UV/vis spectrum. The photoproduct was assigned as the dimeric bis- $\mu$-N-bridged species based on the ${ }^{1} \mathrm{H}$ NMR spectrum; however it is unclear at this point whether this observation precludes the viability of both bond dissociation pathways for the $\mathrm{W}$ complex.

In summary, all experimentally characterised dinitrogen photoactivation catalysts share the same linear geometry of the $\mathrm{M}_{2}\left(\mu-\mathrm{N}_{2}\right)$ core. Importantly, there are indications that the dinitrogen photoactivation pathway is bifurcated in some systems, implying that $\mathrm{M}-\mathrm{N}$ and $\mathrm{N}-\mathrm{N}$ bond scission processes compete. 


\section{Mechanistic aspects in thermal and photochemical dinitrogen activation}

Many papers and reviews have been dedicated to the question of how thermal dinitrogen activation proceeds on the molecular level, ${ }^{81-87}$ most notably the Chatt ${ }^{88}$ and Schrock ${ }^{89}$ cycles, which cannot be repeated here. We focus below on mechanistic aspects of the families of complexes that are capable of thermal and photochemical dinitrogen activation, and review available computational studies on dinitrogen photofixation.

A computational study by Reiher et al. ${ }^{59}$ investigated the second scenario put forward by Fischler and von Gustorf (Fig. 3), namely an electronic excitation that leads to an excited state with an altered electronic and geometric structure in which the $\mu-\mathrm{N}$ can be protonated more easily. The individual steps involved were laid out as (i) coordination of $\mathrm{N}_{2}$ without a requirement for bond weakening, (ii) formation of a welldefined excited state that activates the bound $\mathrm{N}_{2}$ by populating an antibonding orbital, e.g. a $\pi^{*}$ orbital, Fig. $6 \mathrm{a}$, and (iii) protonation of the thus formed diazenoid structure and subsequent reduction; whether the protons are already stored in the complex before the activation step or the protonation takes place after light activation is open. ${ }^{59}$ With such a dinitrogen reduction and protonation scenario in mind, Sellmann-type complexes of $\mathrm{Fe}$ and $\mathrm{Ru}$ (see above) were chosen as models for this theoretical study, in which the thiolate ligand can be protonated and thus act as an 'internal acid'.

Using DFT, TD-DFT and MP2 methods, it was found that the LUMO of the linear $\mathrm{M}-\mathrm{N}-\mathrm{N}-\mathrm{M}$ core is dominated by $\mathrm{N}-\mathrm{N}$ $\pi^{*}$ character, and that the geometry resulting from its occupation has bent $\mathrm{M}-\mathrm{N}-\mathrm{N}$ units $\left(\mathrm{ca} .131-147^{\circ}\right)$ akin to the 'zigzag' transition state in thermal dinitrogen activation, Fig. $2 \mathrm{~b}$. The bridging nitrogen atoms begin to form lone pairs in the excited state, Fig. 6a, which was shown to facilitate their protonation by the internal acids. ${ }^{59}$ The same geometric distortion as in the structure with a doubly occupied LUMO was found for an excited triplet state, implying that several types of exci-
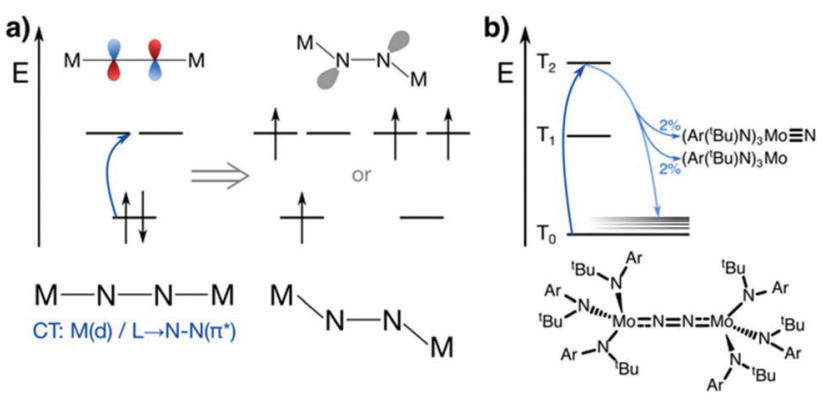

Fig. 6 (a) Photoactivation scheme proposed by Reiher et al.: formation of an excited state in which the LUMO of $\mathrm{N}-\mathrm{N} \pi^{*}$ character is singly or doubly occupied (total spin unspecified), resulting in an excited state geometry that has lone pairs at the $\mu-\mathrm{N}$ atoms which facilitate protonation. (b) Photochemical pathways seen by Huss et al. for the LaplazaCummins complex: excitation into the second excited triplet state (dark blue), rapid internal conversion and vibrational relaxation (light blue) with $2 \%$ cleavage of $\mathrm{M}-\mathrm{N}$ and $2 \%$ cleavage of $\mathrm{N}-\mathrm{N}$ bonds. tation may in principle be relevant to dinitrogen photoactivation. The character of the orbitals involved in the activation process in this study are dominated by the $\mathrm{M}_{2} \mathrm{~N}_{2}$ core, regardless of the metal and the protonation state of the ligand. There is a striking resemblance to many other complexes of similar geometry for which electronic structure analyses have since been published, e.g. for several of the Nishibayashi systems in which the HOMO is of $\mathrm{M}-\mathrm{N} \pi^{*}$ and $\mathrm{N}-\mathrm{N} \pi$ character. ${ }^{58,90}$ Of course, other complexes are known to have different HOMO and LUMO character, e.g. the Laplaza-Cummins system in which the HOMO is of M-N $\pi$ and $\mathrm{N}-\mathrm{N} \pi^{*}$ and the LUMO is of $\mathrm{M}-\mathrm{N} \pi^{*}$ and $\mathrm{N}-\mathrm{N} \pi$ character, as characterised by DFT later. ${ }^{56}$ As noted in Reiher et al. ${ }^{59}$ the vertical excitation into a $\mathrm{N}_{2}$ $\pi^{*}$ orbital may be a universal process that enables dinitrogen activation and subsequent protonation for many linear $\mathrm{M}_{2}-\mu-$ $\mathrm{N}_{2}$ complexes - provided of course they have an appropriate electronic structure.

Theoretical studies on the mechanism of thermal dinitrogen splitting with the Laplaza/Cummins complex have shown that the steric bulk of the ligands is important for stabilising the $\left[(\operatorname{NRAr})_{3} \operatorname{Mo}\left(\mathrm{N}_{2}\right)\right]$ adduct, and that the energetics of the reaction are sensitive to the ligand and metal properties. ${ }^{91}$ The $\left[(\mathrm{NRAr})_{3} \mathrm{Mo}\left(\mu-\mathrm{N}_{2}\right) \mathrm{Mo}(\mathrm{NRAr})_{3}\right]$ dimer is a triplet in its electronic ground state according to magnetic susceptibility measurements ${ }^{56}$ although computational studies indicate that ligand rotations may result in a favourable singlet ground state depending on the nature of $\mathrm{R}\left({ }^{t} \mathrm{Bu}\right.$ or $\left.{ }^{\mathrm{i}} \mathrm{Pr}\right) \cdot{ }^{92}$ Several independent studies have found that a zig-zag transition state, i.e. substantial deviation from a linear Mo-N-N-Mo core with Mo-N$\mathrm{N}$ angles of $c a .130^{\circ}$ (Fig. 2b), is formed en route to cleaving the $\mathrm{N}-\mathrm{N}$ bond. ${ }^{91,93}$ This structure has a significantly elongated $\mathrm{N}-\mathrm{N}$ separation of $c a$. $1.56 \AA$ compared with $1.20 \AA$ in the ground state, and undergoes $\mathrm{N}-\mathrm{N}$ scission. ${ }^{91}$ The importance of a careful design of the metal environment was emphasised early by Morokuma and coworkers: a Mo dimer with an amine ligand trans to the $\mu-\mathrm{N}_{2}$ bridge does not split $\mathrm{N}_{2}, \uparrow$ likely due to the competing $\sigma$-donation effects of the amine with the $\mathrm{N}_{2}$ ligand.

The Laplaza/Cummins system is also the only one for which the photophysical and photochemical processes underpinning dinitrogen photoactivation have been investigated experimentally. ${ }^{75}$ Having observed two photoproducts, indicative of a bifurcated reaction path (see above), ${ }^{56}$ a subsequent time-resolved spectroscopy study ${ }^{75}$ set out to map the processes at greater time resolution ( $60 \mathrm{fs}$ ). The initial excitation at $2.3 \mathrm{eV}$ primarily results in the population of the second excited triplet state from the triplet ground state, shifting electron density from an orbital with $\mathrm{Mo}-\mathrm{N} \pi$ and $\mathrm{N}-\mathrm{N} \pi^{*}$ character to one with predominant Mo-N $\pi^{*}$ and $\mathrm{N}-\mathrm{N} \pi$ character according to DFT calculations. The excited state decays rapidly via internal conversion (IC) to the ground state (300 fs), followed by vibrational cooling ( $<1 \mathrm{ps})$, and the dissociation takes

$\dagger$ Dinitrogen splitting with this molybdenum dimer, $\left[\left({ }^{t} \mathrm{BuMe}_{2} \mathrm{SiNCH}_{2} \mathrm{CH}_{2}\right)_{3} \mathrm{Mo}(\mu\right.$ $\left.\left.\left.\mathrm{N}_{2}\right) \mathrm{Mo}^{t}{ }^{\mathrm{B} u M e}{ }_{2} \mathrm{SiNCH}_{2} \mathrm{CH}_{2}\right)_{3}\right]$, is computed to be endothermic by $10 \mathrm{kcal} \mathrm{mol}^{-1}$. ${ }^{-3}$ 
place before complete vibrational cooling is achieved, Fig. $6 \mathrm{~b} .{ }^{75}$ The authors rationalise the rapid deactivation of the excited state not with a dissociative excited state that returns to the ground state via solvent cage recombination, but rather with direct internal conversion to a vibrationally excited ground state. This assessment is based on the excited state not having the $\sigma^{*}$ character and high yields usually seen for such impulsive bond breaking processes, as well as the nearly equal amounts of $\mathrm{N}-\mathrm{N}$ and $\mathrm{Mo}-\mathrm{N}$ cleavage products observed. If the excited state did indeed break the Mo-N bond and recombined to form the dimer in the solvent cage, equal yields of $\mathrm{N}-\mathrm{N}$ and Mo-N cleavage products would only be consistent with equal barriers for these two bond cleavage processes - whereas in fact it is known that $\mathrm{N}-\mathrm{N}$ cleavage is associated with higher barriers in the ground state than Mo-N cleavage. The authors thus consider the most likely scenario that bond cleavage and vibrational energy relaxation compete once the system has reached the ground state via IC. ${ }^{75}$ Relaxation to the ground state is dominant, and Mo-N and $\mathrm{N}-\mathrm{N}$ bond cleavage processes each make up ca. $2 \%$ of the dissociation channels, Fig. 6b. The fact that equal amounts of Mo-N and $\mathrm{N}-\mathrm{N}$ bond dissociation products are observed is presumably due to the vibrational energy distribution during IC, which does not follow the statistics expected from thermal barriers. This inherent bias towards $\mathrm{N}-\mathrm{N}$ cleavage rather than Mo-N cleavage is exciting, as it implies that modifications of the system that impede vibrational relaxation and dissociation into reactants would improve the overall yield of the Mo-N product. ${ }^{75}$

Sita and coworkers recently noted that the photochemical reactions of the tungsten and molybdenum complexes $\left(\left[\mathrm{L}\left(\mathrm{Cp}^{*}\right)\right.\right.$ $\left.\left.\mathrm{M}\left(\mu-\mathrm{N}_{2}\right) \mathrm{M}\left(\mathrm{Cp}^{*}\right) \mathrm{L}\right], \mathrm{L}=\mathrm{N}\left({ }^{\mathrm{i}} \mathrm{Pr}\right) \mathrm{C}(\mathrm{Me}) \mathrm{N}\left({ }^{\mathrm{i}} \mathrm{Pr}\right)\right)$ are slow and suffer from poor efficiency and atom economy. An additional obstacle to further developing this chemistry was the unknown mechanism of the photochemical pathway. ${ }^{94}$ Having identified a correlation between the ligand size and the degree of $\mathrm{N}_{2}$ activation in $\mathrm{Hf}$ and Ta complexes, they reduced the steric bulk of the ligand $\left(\mathrm{N}\left({ }^{\mathrm{i}} \mathrm{Pr}\right) \mathrm{C}(\mathrm{Me}) \mathrm{N}\left({ }^{\mathrm{i}} \mathrm{Pr}\right)\right.$ to $\left.\mathrm{N}(\mathrm{Et}) \mathrm{C}(\mathrm{Ph}) \mathrm{N}(\mathrm{Et})\right)$ and found that, as expected, the Mo and $\mathrm{W}$ complexes switched to thermal dinitrogen cleavage. ${ }^{94}$ Along the thermal route, the bis- $\mu$-N-bridged $\mathrm{Mo}^{\mathrm{V}}$ dimer $\left[\mathrm{Cp}^{*} \mathrm{LMo}^{\mathrm{V}}(\mu-\mathrm{N})_{2} \mathrm{Mo}^{\mathrm{V}} \mathrm{LCp}^{*}\right]$ with $\mathrm{L}=$ $\mathrm{N}(\mathrm{Et}) \mathrm{C}(\mathrm{Ph}) \mathrm{N}(\mathrm{Et})$ is found, the analogue of which with $\mathrm{L}=$ $\mathrm{N}\left({ }^{\mathrm{i}} \mathrm{Pr}\right) \mathrm{C}(\mathrm{Me}) \mathrm{N}\left({ }^{\mathrm{i}} \mathrm{Pr}\right)$ has been crystallised from the photochemical dinitrogen cleavage reaction (see Fig. 4). The isomerisation coordinate of a simplified model of the analogous Ta dimer was suggested to involve an end-on/side-on bridging core, $\mathrm{M}_{2}\left(\mu-\eta^{2}: \eta^{1}-\mathrm{N}_{2}\right)$, and a side-on/side-on bridging dimer, $\mathrm{M}_{2}\left(\mu-\eta^{2}: \eta^{2}-\mathrm{N}_{2}\right) \cdot{ }^{93,95}$ It is currently unclear whether the first intermediate with $\mathrm{M}_{2}\left(\mu-\eta^{2}: \eta^{1}-\mathrm{N}_{2}\right)$ is also relevant to the thermal isomerisation of the molybdenum dimer, although the otherwise similar chemistry of the Sita series certainly suggests that this may be the case. This would then open the question of whether such a side-on/end-on intermediate is also reached photochemically when irradiating ([L(Cp*) $\mathrm{M}(\mu-$ $\left.\left.\left.\mathrm{N}_{2}\right) \mathrm{M}\left(\mathrm{Cp}^{*}\right) \mathrm{L}\right], \mathrm{L}=\mathrm{N}\left({ }^{\mathrm{i}} \mathrm{Pr}\right) \mathrm{C}(\mathrm{Me}) \mathrm{N}\left({ }^{\mathrm{i}} \mathrm{Pr}\right)\right)$, as opposed to a 'zig-zag'intermediate. Clearly, these are not the only possibilities, an obvious alternative being direct photoisomerisation into the
$\mathrm{M}_{2}(\mu-\mathrm{N})_{2}$ core, which would be consistent with the observation of an irradiation induced change in coordination mode from end-on to side-on in isolated $\mathrm{TiN}_{2}$ complexes. ${ }^{96}$

Computationally, the characterisation of photochemical reaction coordinates for transition metal complexes is highly challenging. The first computational study on a complex that is known to be active in dinitrogen photoactivation focused on the $\left[\mathrm{Os}_{2}^{(\mathrm{II}, \mathrm{III})}\left(\mu-\mathrm{N}_{2}\right)\left(\mathrm{NH}_{3}\right)_{10}\right]^{5+}$ dimer by Kunkely and Vogler. ${ }^{60}$ Using multireference CASPT2/CASSCF methods considering spin-orbit coupling, we characterised the electronic ground state and excited doublet and quartet states at the equilibrium geometry, and the evolution of the electronic structure of the twelve lowest-lying states along the $\mathrm{N}-\mathrm{N}$ dissociation coordinate. It is clear from a purely MO-based picture that a molecular orbital of $\mathrm{N}-\mathrm{N} \sigma^{*}$ character would be the one that is energetically most affected along the dissociation coordinate, Fig. 7. Indeed, a stepwise increase in $\mathrm{N}-\mathrm{N}$ distance resulted in drastic changes of the electronic structure, in particular related to electronic states in which an orbital of $\sigma$ character between osmium and $\mu-\mathrm{N}$ atoms and $\sigma^{*}$ character between the two $\mu-\mathrm{N}$ bridges becomes first singly, then doubly occupied. Additionally, the in silico description of the $\mathrm{N}-\mathrm{N}$ separation process allows for a quantitative evaluation of electronic structure descriptors such as bond orders and relative orbital occupation numbers. ${ }^{60}$ Clearly, more research is needed to fully map other dissociation coordinates and competing processes. However, it is of note for the following discussion that in our computational analysis of this osmium dimer a significant number of doubly excited determinants were seen below the experimentally determined energy that induces $\mathrm{N}-\mathrm{N}$ scission. $^{60}$

Having presented an overview of the currently available experimental and computational insights into dinitrogen photoactivation, we can now differentiate two scenarios for light-induced activation of the $\mathrm{N}-\mathrm{N}$ triple bond and suggest types of excitation that would most likely facilitate the implementation of these scenarios. Firstly, in the scenario of

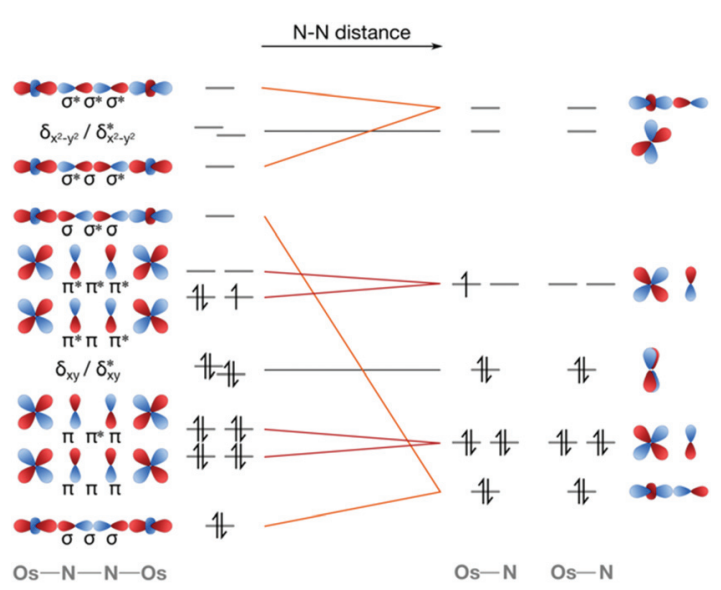

Fig. 7 Molecular orbital scheme of the linear dinitrogen cleavage coordinate from a Os ${ }_{2}^{(I I, I I I)}(\mu-\mathrm{N})_{2}$ core with octahedrally coordinated metals as in $\left[\mathrm{Os}_{2}^{(\mathrm{II}, \mathrm{III})}\left(\mu-\mathrm{N}_{2}\right)\left(\mathrm{NH}_{3}\right)_{10}\right]^{5+}$ to two independent OsN monomers. 
Reiher et al. the protonation of the $\mu-\mathrm{N}$ bridges requires an activated bridge with an onset of lone pair formation. This may be achieved with excitations into $\mathrm{N}-\mathrm{N} \pi^{*}$ orbitals (Fig. 8, left). When aiming at full dinitrogen photocleavage, the excitation should probably aim at orbitals of $\mathrm{N}-\mathrm{N} \sigma^{*}$ character, which will most likely lie higher in energy than the $\pi^{*}$ orbitals as shown schematically on the right of Fig. 8. Alternatively, an excited state with a different type of acceptor orbital may lead to a geometry in which an MO of significant $\mathrm{N}-\mathrm{N} \sigma^{*}$ character is lowered sufficiently in energy to allow its occupation, which would be a more indirect route to dinitrogen photocleavage.

For either scenario, one may also consider which type of orbital the electron(s) should ideally originate from to maximise the degree of activation. In the first scenario, distortion of the molecule into a zig-zag geometry can be achieved by a charge-transfer excitation from a ligand-based orbital as shown by Reiher et al. It can also be hypothesized that an excitation from a N-N $\pi$ orbital might be effective, as it would weaken the $\mathrm{N}-\mathrm{N}$ interaction twofold. With the $\mathrm{N}-\mathrm{N} \sigma \mathrm{MO}$ as the dominant remaining bonding interaction between the $\mathrm{N}-\mathrm{N}$ bridges, rotations about this axis might be less hindered than in the ground state. For full N-N photoscission into two metal nitrido complexes, the most effective donor orbital would likely be one of $\mathrm{N}-\mathrm{N}$ bonding character $(\sigma$ or $\pi$ ), as this would deplete a bonding orbital of electrons while populating an antibonding orbital.

These considerations are based on a rather simplified oneelectron picture that considers the ground state molecular orbitals, rather than the actual excited state which may of course have significant multireference character. Furthermore, any coupling between close-lying excited states, population

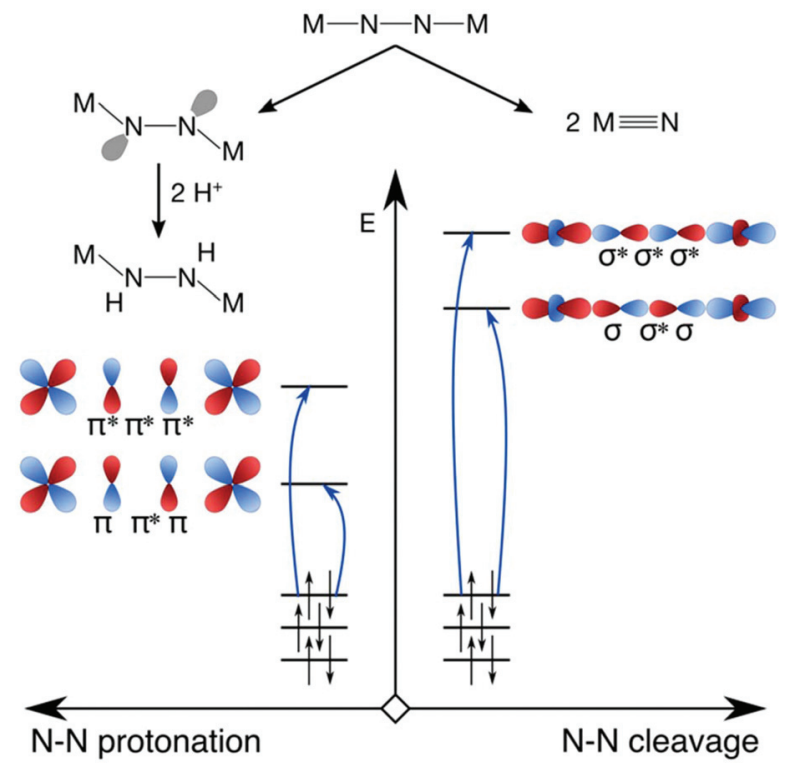

Fig. 8 Hypothetical scenarios for dinitrogen photoactivation that would lead to $\mu-\mathrm{N}$ protonation (left) and $\mathrm{N}-\mathrm{N}$ scission (right). The character of the donor orbitals is discussed in the text. transfer during the dynamic relaxation processes and vibrational relaxation are not taken into account, meaning that other types of excitation may lead to either scenario if dynamic processes induce particular distortions or vibrations that lower the above-mentioned virtual orbitals such that their occupation becomes possible. Nevertheless, the chemically intuitive ground state molecular orbital point of view may help in identifying other systems that might be amenable to either of the dinitrogen photoactivation coordinates. For instance, if particularly bright and/or isolated bands in the UV-vis spectrum of a compound are due to excitations that are dominated by configurations in which such orbitals are singly or doubly occupied, the candidate may be a good test case for dinitrogen photoactivation.

\section{Conclusions}

This contribution was aimed at summarising the current status of research into dinitrogen photoactivation. The six complexes known to be capable of dinitrogen photoactivation share as a common characteristic of a linear $\mathrm{M}-\mathrm{N}-\mathrm{N}-\mathrm{M}$ core, in which the metal ions are tetrahedrally or octahedrally coordinated. There is direct evidence for a bifurcated reaction pathway in one of these complexes, resulting in products due to the desired $\mathrm{N}-\mathrm{N}$ as well as the unproductive $\mathrm{M}-\mathrm{N}$ bond cleavage. The reaction products of other dinitrogen photoactivation experiments indicate that bifurcated reaction pathways may be a common feature of this reaction. The main challenge appears to be the suppression of undesired side reactions while maximising the yield of metal-nitrido or $\mathrm{NR}_{\mathrm{x}}$ products. To date, two computational studies have begun to explore the electronic structures of the ground and excited states of complexes that are relevant to dinitrogen photoactivation. Compared with thermal dinitrogen activation, however, this line of research is relatively unexplored territory, and detailed experimental studies on all photochemical and photophysical processes would certainly be desirable to further advance our understanding of the underlying mecha$\operatorname{nism}(\mathrm{s})$.

While acknowledging that the excited state dynamics of the entire dinitrogen photoactivation process will inevitably be very challenging to resolve, an analysis of the known dinitrogen photocleavage catalysts has highlighted features that may help to identify more complexes susceptible to light-induced $\mathrm{N}_{2}$ activation: if electronic excitations into $\mathrm{N}-\mathrm{N}$ antibonding orbitals are associated with high spectral intensities, irradiation of these bands may lead to an excited state distortion of 'zig-zag' shape and facilitate protonation of the $\mu-\mathrm{N}$ atoms in case of $\mathrm{N}-\mathrm{N} \pi^{*}$ character, while for $\mathrm{N}-\mathrm{N} \sigma^{*}$ character the excited state may decay into metal nitrido complexes. From a computational point of view, the steps toward unravelling the functional principles of photochemical dinitrogen activation include the identification of relevant excited states, mapping possible dissociation pathways, and studying the dynamic dissociation processes. 


\section{Conflicts of interest}

There are no conflicts to declare.

\section{Acknowledgements}

This work was carried out with a $50^{\text {th }}$ Anniversary Prize Fellowship from the University of Bath and was initially supported by a H2020 Marie-S.-Curie Individual Fellowship of the European Commission, call H2020-MSCA-IF-2015, proposal number 703860, title: Solar Dinitrogen Activation, acronym: SolarAct. The COST action CM1305 "Explicit Control Over Spin-states in Technology and Biochemistry (ECOSTBio)" is gratefully acknowledged for network support.

\section{Notes and references}

1 J. Chatt and G. J. Leigh, Chem. Soc. Rev., 1972, 1, 121-144.

2 F. Haber, in Fünf Vorträge aus den Jahren 1920-1923, 1924, vol. 1, pp. 1-24.

3 G. Ertl, Angew. Chem., Int. Ed., 2008, 47, 3524-3535.

4 O. Einsle, F. A. Tezcan, S. L. Andrade, B. Schmid, M. Yoshida, J. B. Howard and D. C. Rees, Science, 2002, 297, 1696-1700.

5 K. M. Lancaster, M. Roemelt, P. Ettenhuber, Y. Hu, M. W. Ribbe, F. Neese, U. Bergmann and S. DeBeer, Science, 2011, 334, 974-977.

6 T. Spatzal, M. Aksoyoglu, L. Zhang, S. L. Andrade, E. Schleicher, S. Weber, D. C. Rees and O. Einsle, Science, 2011, 334, 940.

7 C. E. Laplaza and C. C. Cummins, Science, 1995, 268, 861863.

8 E. Solari, C. Da Silva, B. Iacono, J. Hesschenbrouck, C. Rizzoli, R. Scopelliti and C. Floriani, Angew. Chem., Int. Ed., 2001, 40, 3907-3909.

9 N. Cherkasov, A. O. Ibhadon and P. Fitzpatrick, Chem. Eng. Process. Process Intensif., 2015, 90, 24-33.

10 R. Schlögl, Angew. Chem., Int. Ed., 2003, 42, 2004-2008.

11 S. Paul, N. Cox and D. A. Pantazis, Inorg. Chem., 2017, 56, 3875-3888.

12 V. Krewald, M. Retegan and D. A. Pantazis, Top. Curr. Chem., 2016, 371, 23-48.

13 I. Djurdjevic, O. Einsle and L. Decamps, Chem. - Asian J., 2017, 12, 1447-1455.

14 C. C. Lee, M. W. Ribbe and Y. Hu, Met. Ions Life Sci., 2014, 14, 147-176.

15 B. M. Hoffman, D. Lukoyanov, Z. Y. Yang, D. R. Dean and L. C. Seefeldt, Chem. Rev., 2014, 114, 4041-4062.

16 I. Klopsch, M. Finger, C. Würtele, B. Milde, D. B. Werz and S. Schneider, J. Am. Chem. Soc., 2014, 136, 6881-6883.

17 M. G. Scheibel, J. Abbenseth, M. Kinauer, F. W. Heinemann, C. Wurtele, B. de Bruin and S. Schneider, Inorg. Chem., 2015, 54, 9290-9302.
18 G. A. Silantyev, M. Förster, B. Schluschaß, J. Abbenseth, C. Würtele, C. Volkmann, M. C. Holthausen and S. Schneider, Angew. Chem., Int. Ed., 2017, 56, 5872-5876.

19 R. Bjornsson, F. Neese, R. R. Schrock, O. Einsle and S. DeBeer, J. Biol. Inorg. Chem., 2015, 20, 447-460.

20 I. Dance, Dalton Trans., 2010, 39, 2972-2983.

21 B. M. Barney, H. I. Lee, P. C. Dos Santos, B. M. Hoffman, D. R. Dean and L. C. Seefeldt, Dalton Trans., 2006, 2277-2284.

22 B. M. Hoffman, D. Lukoyanov, D. R. Dean and L. C. Seefeldt, Acc. Chem. Res., 2013, 46, 587-595.

23 Y. Hu and M. W. Ribbe, Angew. Chem., Int. Ed., 2016, 55, 8216-8226.

24 R. J. Burford and M. D. Fryzuk, Nat. Rev. Chem., 2017, 1, 0026.

25 J. M. Smith, in Progress in Inorganic Chemistry, John Wiley \& Sons, Inc., 2014, vol. 58, pp. 417-470.

26 C. Rebreyend and B. de Bruin, Angew. Chem., Int. Ed., 2015, $54,42-44$.

27 B. Peigne and G. Aullon, Acta Crystallogr., Sect. B: Struct. Sci., Cryst. Eng. Mater., 2015, 71, 369-386.

28 P. L. Holland, Dalton Trans., 2010, 39, 5415-5425.

29 M. D. Fryzuk and S. A. Johnson, Coord. Chem. Rev., 2000, 200-202, 379-409.

30 R. M. Badger, J. Chem. Phys., 1934, 2, 128-131.

31 A. J. Keane, W. S. Farrell, B. L. Yonke, P. Y. Zavalij and L. R. Sita, Angew. Chem., Int. Ed., 2015, 54, 10220-10224.

32 M. E. Vol'Pin and V. B. Shur, Nature, 1966, 209, 1236-1236.

33 D. V. Yandulov and R. R. Schrock, J. Am. Chem. Soc., 2002, 124, 6252-6253.

34 D. V. Yandulov and R. R. Schrock, Science, 2003, 301, 7678.

35 M. Kol, R. R. Schrock, R. Kempe and W. M. Davis, J. Am. Chem. Soc., 1994, 116, 4382-4390.

36 D. Sellmann and J. Sutter, J. Biol. Inorg. Chem., 1996, 1, 587-593.

37 D. Sellmann and J. Sutter, Acc. Chem. Res., 1997, 30, 460469.

38 D. Sellmann, J. Utz, N. Blum and F. W. Heinemann, Coord. Chem. Rev., 1999, 190-192, 607-627.

39 D. Sellmann, W. Soglowek, F. Knoch and M. Moll, Angew. Chem., Int. Ed. Engl., 1989, 28, 1271-1272.

40 D. Sellmann, B. Hautsch, A. Rösler and F. W. Heinemann, Angew. Chem., Int. Ed., 2001, 40, 1505-1507.

41 D. Sellmann, A. Hille, A. Rosler, F. W. Heinemann, M. Moll, G. Brehm, S. Schneider, M. Reiher, B. A. Hess and W. Bauer, Chem. - Eur. J., 2004, 10, 819-830.

42 Y. Nishibayashi, Dalton Trans., 2012, 41, 7447-7453.

43 K. Arashiba, E. Kinoshita, S. Kuriyama, A. Eizawa, K. Nakajima, H. Tanaka, K. Yoshizawa and Y. Nishibayashi, J. Am. Chem. Soc., 2015, 137, 5666-5669.

44 S. Kuriyama, K. Arashiba, K. Nakajima, H. Tanaka, K. Yoshizawa and Y. Nishibayashi, Eur. J. Inorg. Chem., 2016, 2016, 4856-4861.

45 A. Eizawa, K. Arashiba, H. Tanaka, S. Kuriyama, Y. Matsuo, K. Nakajima, K. Yoshizawa and Y. Nishibayashi, Nat. Commun., 2017, 8, 14874. 
46 Y. Roux, C. Duboc and M. Gennari, ChemPhysChem, 2017, 18, 2606-2617.

47 M. Holscher and W. Leitner, Chem. - Eur. J., 2017, 23, 11992-12003.

48 M. J. Bezdek and P. J. Chirik, Angew. Chem., Int. Ed., 2016, 55, 7892-7896.

49 R. J. Burford, A. Yeo and M. D. Fryzuk, Coord. Chem. Rev., 2017, 334, 84-99.

50 G. P. Connor and P. L. Holland, Catal. Today, 2017, 286, 21-40.

51 A. Eizawa and Y. Nishibayashi, in Nitrogen Fixation, Springer Verlag, 2017, 60( (10)), pp. 153-169.

52 S. Kuriyama and Y. Nishibayashi, in Nitrogen Fixation, Springer Verlag, 2017, 60( (5)), 215-234.

53 F. Tuczek, in Molybdenum and Tungsten Enzymes, Royal Society of Chemistry, 2016, vol. 6, pp. 223-274.

$54 \mathrm{H}$. Tanaka and K. Yoshizawa, in Nitrogen Fixation, Springer Verlag, 2017, 60( (7)), 171-196.

55 I. Fischler and E. K. von Gustorf, Naturwissenschaften, 1975, 62, 63-70.

56 J. J. Curley, T. R. Cook, S. Y. Reece, P. Müller and C. C. Cummins, J. Am. Chem. Soc., 2008, 130, 9394-9405.

57 H. Kunkely and A. Vogler, Angew. Chem., Int. Ed., 2010, 49, 1591-1593.

58 T. Miyazaki, H. Tanaka, Y. Tanabe, M. Yuki, K. Nakajima, K. Yoshizawa and Y. Nishibayashi, Angew. Chem., Int. Ed., 2014, 53, 11488-11492.

59 M. Reiher, B. Kirchner, J. Hutter, D. Sellmann and B. A. Hess, Chem. - Eur. J., 2004, 10, 4443-4453.

60 V. Krewald and L. Gonzalez, Chem. - Eur. J., 2018, 24, 51125123.

61 A. J. Medford and M. C. Hatzell, ACS Catal., 2017, 7, 26242643.

62 K. Hoshino, M. Inui, T. Kitamura and H. Kokado, Angew. Chem., Int. Ed., 2000, 39, 2509-2512.

63 H. Li, J. Shang, Z. Ai and L. Zhang, J. Am. Chem. Soc., 2015, 137, 6393-6399.

64 T. Oshikiri, K. Ueno and H. Misawa, Angew. Chem., 2016, 55, 3942-3946.

65 Y. Hao, X. Dong, S. Zhai, H. Ma, X. Wang and X. Zhang, Chem. - Eur. J., 2016, 22, 18722-18728.

66 J. M. P. Martirez and E. A. Carter, J. Am. Chem. Soc., 2017, 139, 4390-4398.

67 C.-M. Che, H.-W. Lam, W.-F. Tong, T.-F. Lai and T.-C. Lau, J. Chem. Soc., Chem. Commun., 1989, 1883-1884.

68 D. C. Ware and H. Taube, Inorg. Chem., 1991, 30, 4605-4610.

69 H.-W. Lam, C.-M. Che and K.-Y. Wong, J. Chem. Soc., Dalton Trans., 1992, 1411-1416.

70 O. Krahe, E. Bill and F. Neese, Angew. Chem., Int. Ed., 2014, 53, 8727-8731.

71 M. G. Scheibel, Y. Wu, A. C. Stuckl, L. Krause, E. Carl, D. Stalke, B. de Bruin and S. Schneider, J. Am. Chem. Soc., 2013, 135, 17719-17722.
72 M. G. Scheibel, B. Askevold, F. W. Heinemann, E. J. Reijerse, B. de Bruin and S. Schneider, Nat. Chem., 2012, 4, 552-558.

73 Y. Gloaguen, C. Rebreyend, M. Lutz, P. Kumar, M. Huber, J. I. van der Vlugt, S. Schneider and B. de Bruin, Angew. Chem., Int. Ed., 2014, 53, 6814-6818.

74 T. M. Buscagan, P. H. Oyala and J. C. Peters, Angew. Chem., Int. Ed., 2017, 56, 6921-6926.

75 A. S. Huss, J. J. Curley, C. C. Cummins and D. A. Blank, J. Phys. Chem. B, 2013, 117, 1429-1436.

76 M. J. A. Johnson, P. M. Lee, A. L. Odom, W. M. Davis and C. C. Cummins, Angew. Chem., Int. Ed. Engl., 1997, 36, 8791.

77 M. Hirotsu, P. P. Fontaine, P. Y. Zavalij and L. R. Sita, J. Am. Chem. Soc., 2007, 129, 12690-12692.

78 M. Hirotsu, P. P. Fontaine, A. Epshteyn, P. Y. Zavalij and L. R. Sita, J. Am. Chem. Soc., 2007, 129, 9284-9285.

79 B. L. Yonke, A. J. Keane, P. Y. Zavalij and L. R. Sita, Organometallics, 2011, 31, 345-355.

80 L. M. Duman and L. R. Sita, J. Am. Chem. Soc., 2017, 139, 17241-17244.

81 H. J. Himmel and M. Reiher, Angew. Chem., Int. Ed., 2006, 45, 6264-6288.

82 G. C. Stephan, C. Sivasankar, F. Studt and F. Tuczek, Chem. - Eur. J., 2008, 14, 644-652.

83 J. L. Crossland and D. R. Tyler, Coord. Chem. Rev., 2010, 254, 1883-1894.

84 N. Khoenkhoen, B. de Bruin, J. N. H. Reek and W. I. Dzik, Eur. J. Inorg. Chem., 2015, 2015, 567-598.

85 H. Tanaka, Y. Nishibayashi and K. Yoshizawa, Acc. Chem. Res., 2016, 49, 987-995.

86 F. Studt and F. Tuczek, Angew. Chem., Int. Ed., 2005, 44, 5639-5642.

87 J. Rittle and J. C. Peters, J. Am. Chem. Soc., 2017, 139, 31613170.

88 C. J. Pickett, JBIC, J. Biol. Inorg. Chem., 1996, 1, 601-606.

89 R. R. Schrock, Acc. Chem. Res., 2005, 38, 955-962.

90 H. Tanaka, K. Arashiba, S. Kuriyama, A. Sasada, K. Nakajima, K. Yoshizawa and Y. Nishibayashi, Nat. Commun., 2014, 5, 3737.

91 G. Christian, J. Driver and R. Stranger, Faraday Discuss., 2003, 124, 331-341.

92 G. Christian, R. Stranger, B. F. Yates and D. C. Graham, Dalton Trans., 2005, 962-968.

93 Q. Cui, D. G. Musaev, M. Svensson, S. Sieber and K. Morokuma, J. Am. Chem. Soc., 1995, 117, 1236612367.

94 L. M. Duman, W. S. Farrell, P. Y. Zavalij and L. R. Sita, J. Am. Chem. Soc., 2016, 138, 14856-14859.

95 W. Zhang, Y. Tang, M. Lei, K. Morokuma and D. G. Musaev, Inorg. Chem., 2011, 50, 9481-9490.

96 M. Chen, G. Wang and M. Zhou, Chem. Phys. Lett., 2005, 409, 70-74. 